\title{
Microstructure and Property Investigation of X65MO-316L Hot Rolled Clad Coil Applied for Offshore Line Pipe
}

\section{Tao NIU ${ }^{1,2^{*}}$, Cheng-Gang AN ${ }^{1,2}$, Jia-Ming LUO ${ }^{1,2}$, Xiao-Yong WANG ${ }^{1,2}$ Xiao-Li $\mathrm{DAI}^{1,2}$, Xin-Lang WU ${ }^{3}$, Cai-Xia ZHANG ${ }^{3}$ and Chen $\mathrm{YU}^{3}$}

\author{
${ }^{1}$ Shougang Research Institute of Technology, Shougang Group, Beijing, 100043, China \\ ${ }^{2}$ Beijing Engineering Research Center of Energy Steel Beijing, 100043, China \\ ${ }^{3}$ Shougang Qian'an Iron \&Steel Co. Ltd, Qian’an, Hebei Province, 064404, China \\ *johnniu@126.com
}

\begin{abstract}
Keywords: Clad coil, Mechanical properties, Shear strength, Microstructure, Inclusion, Intergranular Corrosion.
\end{abstract}

\begin{abstract}
In this study, tensile, inter-granular corrosion, and impacting tests were carried out to investigate the mechanical property characteristics of X65MO-316Lclad hot rolled coil trial produced by $2250 \mathrm{~mm}$ hot continuous rolling line, which is applied for the manufacture of offshore line pipe. SEM (Scanning Electron Microscope), TEM (Transmission Electron Microscope) were also used to observe and reveal the microstructure and inclusion of base metal and clad metal. Results show that all the mechanical properties of trial produced clad coil can meet the requirement of specification, and the shear strength reaches about 420MPa. The microstructure of X65MO (base metal) mainly consists of quasi-polygonal ferrite and acicular ferrite with refined and homogenous grain, while that of 316L (clad metal) mainly consist of typical austenite with large deformation. A small amount of ultra-fine recrystallized grains has been found on the boundaries of deformed austenite with $\mathrm{Cr}$ content of about $26 \%$.
\end{abstract}

\section{Introduction}

Pipeline is the most cost-effective way in oil and gas transportation over long distances. As is well known, there are abundant oil and gas resources in the ocean. The exploit and transportation of subsea gas and oil has become one of the most important research highlights, and corrosion protection of $\mathrm{H}_{2} \mathrm{~S} / \mathrm{CO}_{2}$ is essential for offshore line pipe[1 3]. Stainless clad steel is a proper material to solve this problem, and with the good performance of strength and corrosion resistance, it has been widely used in metallurgy, electric power, petrochemical and other fields of serious erosion because of its excellent properties[4, 5].

So far, researches and investigations on clad steel are mainly reported and applied for steel plate production, and lots of them still remain in the experiment stage[6]. However, there are plenty of differences between the deformation during rolling process, as well as the cooling process after coiling for clad coil production. Therefore, in this study, with the production practice of $\mathrm{X} 65 \mathrm{MO}+316 \mathrm{~L}$ clad coil, and characteristics of microstructure and properties have been introduced, in order to provide the theoretical basis and experimental data for development of stainless steel clad coil.

\section{Materials and Methods}

The test material is clad coil hot rolled on $2250 \mathrm{~mm}$ hot continuous rolling line, with the base layer of offshore pipeline steel X65MO, and the clad layer of stainless steel 316L. The chemical compositions are shown in Table 1 . The slab was combined in a symmetrical way with welding seal around it, and then vacuumized to $1 \times 10-1 \mathrm{~Pa}$. After reheated to $1150 \sim 1200^{\circ} \mathrm{C}$, the combined slab was rolled with TMCP two-stage-rolling technology, including finishing rolling temperature of $800 \sim 900^{\circ} \mathrm{C}$ and coiling temperature of $500 \sim 600^{\circ} \mathrm{C}$. 
Table 1. Compositions of experimental materials (wt., \%)

\begin{tabular}{ccccccccc}
\hline Material & $\mathrm{C}$ & $\mathrm{Si}$ & $\mathrm{Mn}$ & $\mathrm{P}$ & $\mathrm{S}$ & $\mathrm{Ni}$ & $\mathrm{Cr}$ & Others \\
\hline X65MO & $0.04 \sim 0.07$ & $0.15 \sim 0.25$ & $1.2 \sim 1.6$ & $\leq 0.015$ & $\leq 0.05$ & -- & $0.1 \sim 0.5$ & $\mathrm{Nb} \mathrm{V} \mathrm{Ti}$ \\
$316 \mathrm{~L}$ & $0.01 \sim 0.02$ & $0.40 \sim 0.60$ & $1.1 \sim 1.2$ & 0.023 & 0.002 & 10.1 & 16.3 & \\
\hline
\end{tabular}

Samples were taken from the coil in the transverse direction, and tensile test for both base metal and the full thickness according to the requirement of "GBT6396-2008" using SHT4605 universal tensile testing machine. Charpy impact test has also been carried out using ZBC-600Cimpact testing machine. Bonding property was tested according to ASTMA264-2003, while inter-granular corrosion test was carried out according to GBT4334-2008. Microstructures of clad coil were observed using SEM and TEM, and precipitates was analyzed using EDS.

\section{Results and Discussion}

Mechanical Properties

Table 2. Mechanical properties of experimental materials

\begin{tabular}{|c|c|c|c|c|c|c|c|}
\hline & \multirow{2}{*}{$R_{\mathrm{t} 0.5} / \mathrm{MPa}$} & \multirow{2}{*}{$R_{\mathrm{m}} / \mathrm{MPa}$} & \multirow{2}{*}{$A_{50.8} / \%$} & \multicolumn{3}{|c|}{ Charpy impact property } & \multirow{2}{*}{$\tau / \mathbf{M P a}$} \\
\hline & & & & Temperature $/{ }^{\circ} \mathrm{C}$ & $K \mathrm{v}_{2} / \mathrm{J}$ & $S A / \%$ & \\
\hline \multirow{2}{*}{ Base metal } & \multirow{2}{*}{530} & \multirow{2}{*}{605} & \multirow{2}{*}{36} & -15 & 113 & 100 & \\
\hline & & & & -30 & 109 & 100 & 420 \\
\hline $\begin{array}{c}\text { Full } \\
\text { thickness }\end{array}$ & 550 & 625 & 41 & -- & -- & -- & \\
\hline
\end{tabular}

Note: $\tau$ represents shear strength.

Sample dimension for Charpy impact test: $5 \mathrm{~mm} * 55 \mathrm{~mm} * 10 \mathrm{~mm}$.

The mechanical properties of the experimental samples are shown in Table 2.The yield strength reaches $530 \mathrm{MPa}$ for base metal while tensile strength reaches $605 \mathrm{MPa}$, which can meet the requirement for X65MO according to API 5L specification. Especially, the base metal shows a great performance of toughness. Even with the half size samples, the impact energy reaches over $110 \mathrm{~J}$ at $-15^{\circ} \mathrm{C}$, and remains almost the same at $-30^{\circ} \mathrm{C}$ with $100 \%$ of shear area. With the contribution of $316 \mathrm{~L}$ clad steel to strength, the yield and tensile strength are $20 \mathrm{MPa}$ higher than that of base metal only, respectively. And as for the interfacial shear strength, the main performance index to evaluate interfacial bonding property between the base layer and the clad layer, reaches $420 \mathrm{MPa}$, almost 2 times higher than the minimum shear strength210 MPa according to GB/T 8165-2008.

\section{Inter-granular Corrosion Property}

Inter-granular corrosion property has been tested according to GBT4334-2008. It is found that there is no crack on the bending surface after inter-granular corrosion test, which shows that under rolling technology employed in this article, the corrosion resistance performance of trialed produced clad coil is great. 


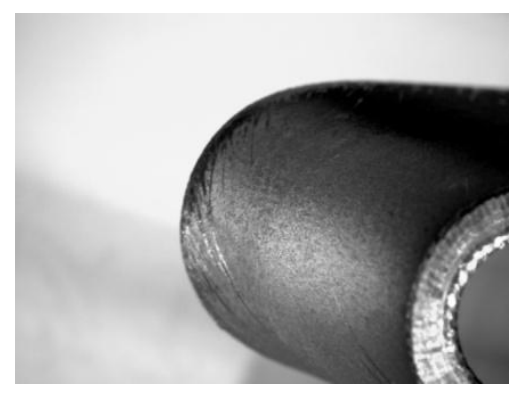

Fig. 1. Bending surface of sample after Inter-granular corrosion test

\section{Microstructure of Base Metal}
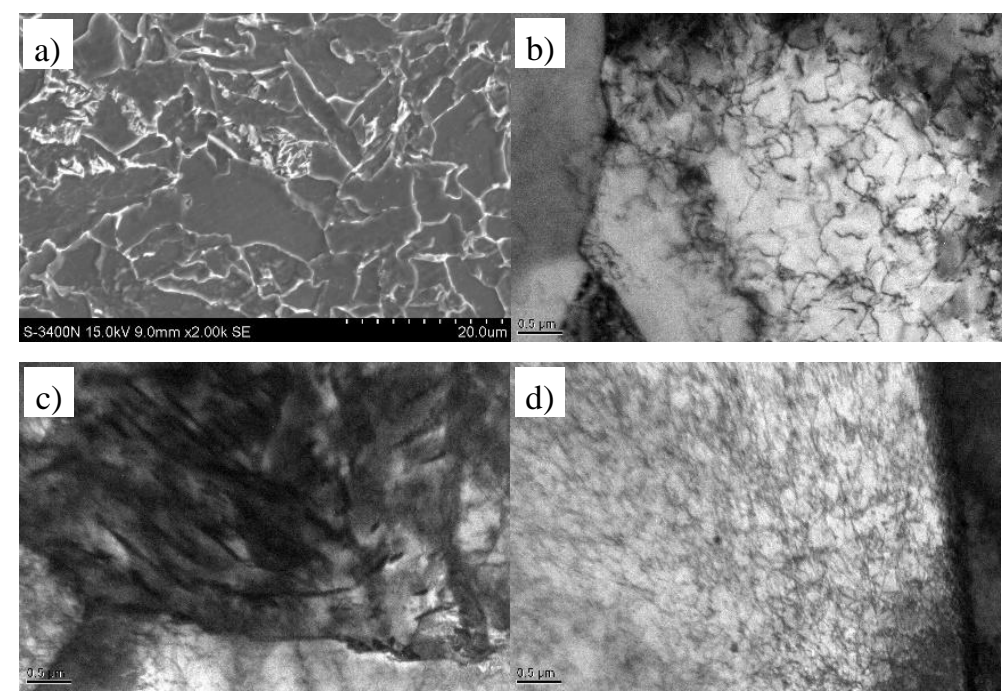

Fig. 2. Microstructure of base metal

a) SEM microstructure; b) dislocations in QF; c) acicular ferrite; d) dislocations in AF

The microstructure of base metal mainly consists of quasi-polygonal ferrite (QF) and acicular ferrite (AF), shown in Fig. 2, a). The grain is refined to the average size of about $5 \sim 10 \mu \mathrm{m}$, with small round MA islands homogenously distributing on the matrix. Fig. 2, c) shows the typical acicular ferrite microstructure. Previous investigations have revealed that the acicular ferrite grains with different sizes grow up in different directions. However, no direction is in the dominate place; the reticular boundary of the pre-existing austenite grains disappears gradually, while some of the quasi-polygonal grain boundaries get across the original austenite boundaries and randomly interlace apparently, so the order and the directions are in mess[7]. This characteristic of AF contributes a lot to inhibit the crack propagation, and subsequently increased the toughness of X65MO base metal [8]. The high density of dislocation in AF (Fig. 2, d), tangled with precipitate of $(\mathrm{Nb}, \mathrm{Ti})(\mathrm{C}, \mathrm{N})$, helps the base metal to have a good performance in strength by precipitation hardening effect [9]. 


\section{Microstructure and Inclusion near Bonding Surface}

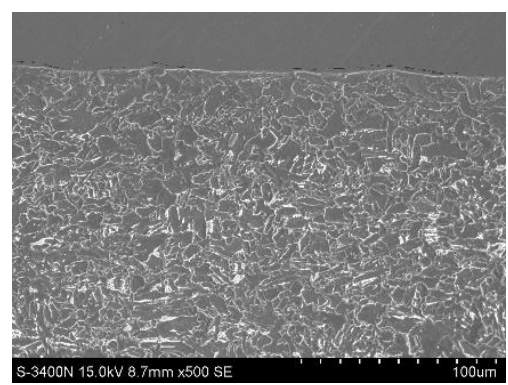

Fig. 3. Microstructure near bonding surface

Through observation of microstructure near the bonding surface (Fig. 3), it can be seen that the decarburized layer with a thickness of $40 \sim 60 \mu \mathrm{m}$ has formed and the carbide vanishes between the interface and normal X65MO microstructure, which has been widely investigated in the previous studies [10]. This is caused by carbon-diffusion from high concentration to stainless steel region in the process of heating and hot rolling.
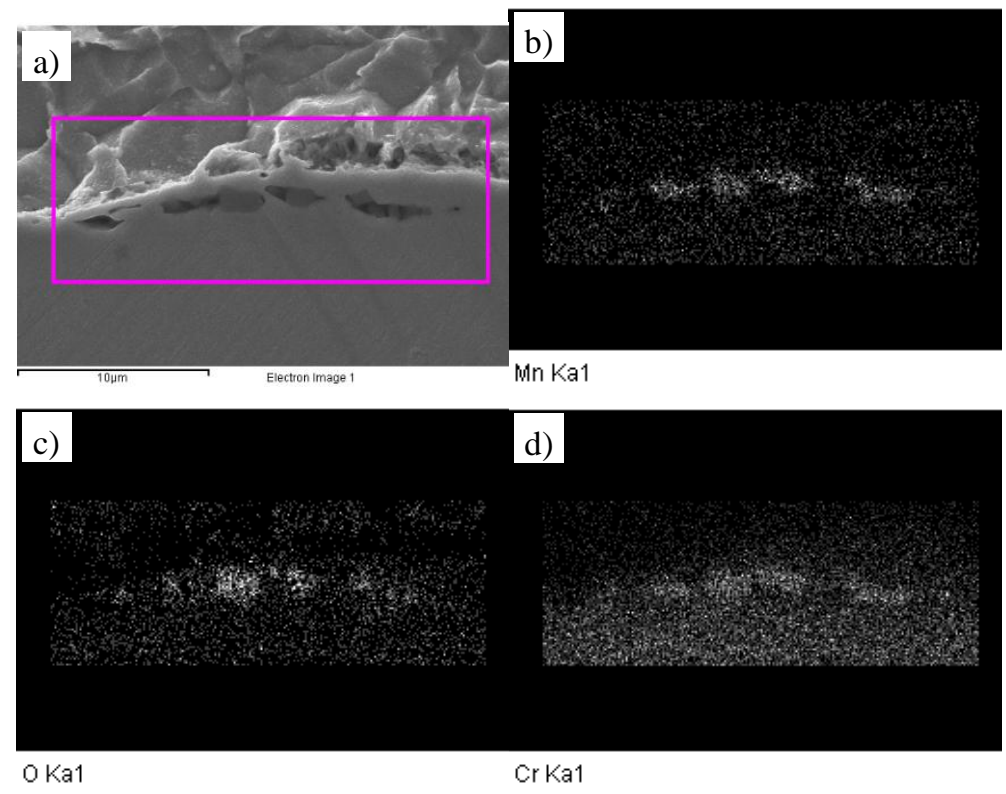

Fig. 4. Inclusion analysis near bonding surface

a) SEM microstructure; b) $\mathrm{Mn}$; c) $\mathrm{O}$; d) $\mathrm{Cr}$

Map scanning was used to analyze the chemical compositions of inclusions near the bonding surface. From the results shown in Fig. 4, those oxides located at original metal surface (OMS)are mainly composed of $\mathrm{O}, \mathrm{Cr}$ and $\mathrm{Mn}$ element in EDS analysis, which might be the spinel structure oxides formed under high oxygen partial pressure [11].However, most of the oxide inclusions are smaller than $5 \mu \mathrm{m}$, and according to investigation of Zhu [11], in the case of light oxidation level, influence of OMS oxides on the mechanical properties should be very little due to its fine size and limited amount. This also explains the good bonding performance of the trial produced clad coil. 


\section{Microstructure of Clad Steel}
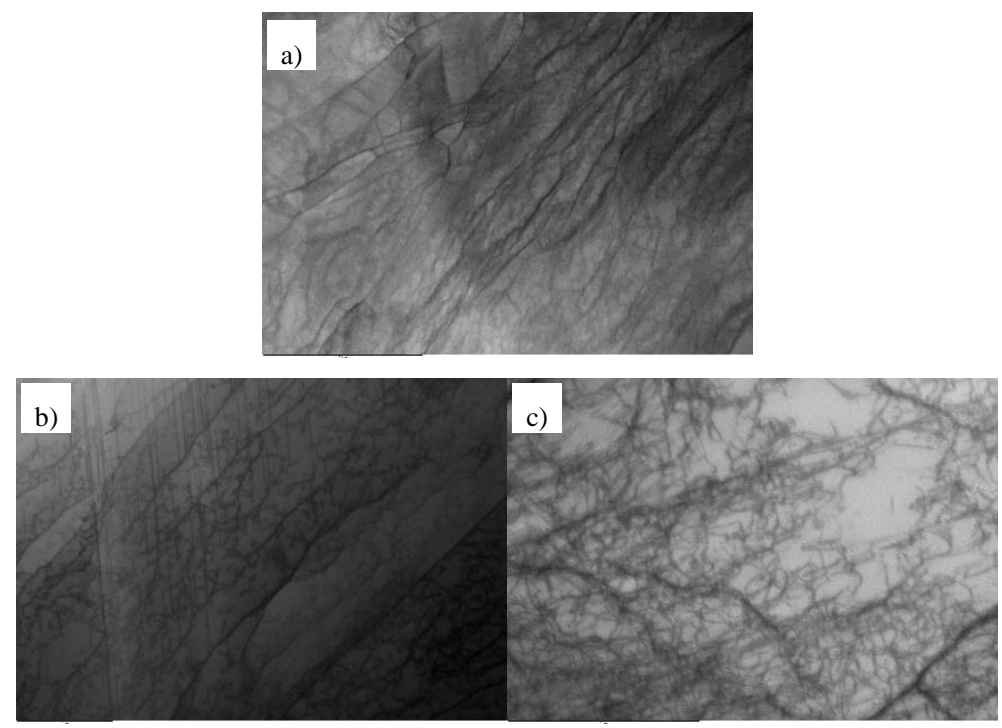

Fig. 5. Microstructure of clad stainless steel

a) deformed austenite; b) twinning structure; c) dislocation

Fig. 5 a) shows the microstructure of clad stainless steel, which mainly consists of austenite after dramatically deformation. Most of the grains have been lengthened along the rolling direction without enough recovery, and there are typical twinning structure (Fig. 5 b) with high density of dislocations within the grain and on the boundaries (Fig. 5 c).

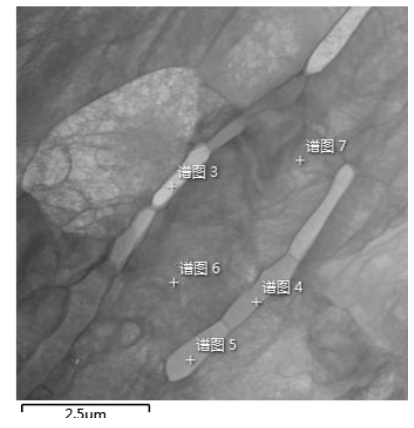

Fig. 6 Recrystallization behavior in clad stainless steel

Table 3. Energy spectrum analysis results

\begin{tabular}{llllll}
\hline & Spectrum & $\begin{array}{l}\text { Spectrum } \\
\mathbf{3}\end{array}$ & $\begin{array}{l}\text { Spectrum } \\
\mathbf{5}\end{array}$ & $\begin{array}{l}\text { Spectrum } \\
\mathbf{6}\end{array}$ & $\begin{array}{l}\text { Spectrum } \\
\mathbf{7}\end{array}$ \\
$\mathbf{C}$ & 1.88 & 1.69 & 1.56 & 1.55 & 1.8 \\
$\mathbf{S i}$ & 0.38 & 0.46 & 0.44 & 0.3 & 0.29 \\
$\mathbf{T i}$ & & 0.33 & & 0.3 & \\
$\mathbf{C r}$ & 25.98 & 25.57 & 25.93 & 19.56 & 19.02 \\
$\mathbf{F e}$ & 62.63 & 62.75 & 62.91 & 66.54 & 66.59 \\
$\mathbf{N i}$ & 3.16 & 3.17 & 3.43 & 7.55 & 7.7 \\
$\mathbf{C u}$ & 2.55 & 2.44 & 2.36 & 2.46 & 2.39 \\
$\mathbf{M o}$ & 3.43 & 3.6 & 3.37 & 1.75 & 2.21 \\
Total & 100 & 100 & 100 & 100 & 100 \\
\hline
\end{tabular}


In this study, an interesting phenomenon has also been found during the observation of microstructure for stainless steel 316L. As is shown in Fig. 6, a small amount of ultra-fine grains has formed on the boundaries of deformed austenite. Energy spectrum analysis results reveals that the content of $\mathrm{Cr}$ in these grains reaches almost $26 \%$, while that of the matrix is only less than $20 \%$. As is well known, the microstructure of $316 \mathrm{~L}$ remain in austenite status during hot rolling process because of the composition, thus phase transformation is impossible. Therefore, in this study, it is defined to be the recrystallization behavior of austenite. However, the deep reason for the composition variation should be investigated further in the future research.

\section{Conclusions}

1. X65MO-316L clad coil has been successfully trial produced by $2250 \mathrm{~mm}$ hot continuous rolling line, which is applied for the manufacture of offshore line pipe. Combined mechanical properties, including tensile strength, impacting toughness and inter-granular corrosion resistance can meet the requirement of specification, especially the shear strength reaches $420 \mathrm{MPa}$, which shows a good performance of bonding property.

2. The microstructure of base metal mainly consists of quasi-polygonal ferrite (QF) andacicular ferrite (AF), with small round MA islands homogenously distributing on the matrix. Overlapped grain boundaries and high density of dislocation in $\mathrm{AF}$, tangled with precipitate of $(\mathrm{Nb}, \mathrm{Ti})(\mathrm{C}, \mathrm{N})$ helps the base metal to have a good performance in strength.

3.Near the bonding surface, there is a decarburized layer with thickness about 40 60 $\mu \mathrm{m}$, as well as some refined oxides composed of $\mathrm{O}, \mathrm{Cr}$ and $\mathrm{Mn}$. However, most of the oxide inclusions are smaller than $5 \mu \mathrm{m}$. So the influence on mechanical properties will be very little.

4. The microstructure of clad stainless steel mainly consists of dramatically deformed austenite with high density of dislocations and typical twinning structure. A small amount of ultra-fine recrystallized grains has been found on the boundaries of deformed austenite with $\mathrm{Cr}$ content of about $26 \%$.

\section{References}

[1] C. D. Waard, U. Lotz, and D. E. Milliams. Predictive Model for CO2 Corrosion Engineering in Wet Natural Gas Pipelines. Corrosion, 1991,47(12): 976-985

[2] R. E. Melchers. The effect of corrosion on the structural reliability of steel offshore structures. Corrosion Science, 2005(47): 2391-2410

[3] R. Barker, Y. Hua \& A. Neville. Internal corrosion of carbon steel pipelines for dense-phase $\mathrm{CO} 2$ transport in carbon capture and storage (CCS) - a review. International Materials Reviews, 2017, 62(1): 1-31

[4] L. Li, F.X. Yin, K. Nagai, Progress of laminated materials and clad steels production, Science Form. 2011 (675-677): 439-447.

[5] J.O. Cross, R.L. Opila, I.W. Boyd, et al, Materials characterization and the evolution of materials.Mrs. Bulletin, 2015 (40): 1019-1034.

[6] Long Li, Zhi-chao. Zhu, Xin-jin. Zhang, Hui-yunLiu. Experimental Study on Hot Rolled Stainless Steel Clad Plate Produced by TMCP. Journal of Materials Engineering, 2015,43(7): 6297(In Chinese)

[7] Tao Niu, Hao Yu, Yong-lin Kang, Ming-jian Long. Research on the accurate control of initial and finishing cooling temperatures for X70 pipeline steels. Materials Science Forum. 2008 (575578) :1038-1043 
[8] Y. M. Kim, H. Lee, N. J. Kim. Transformation behavior and microstructural characteristics of acicular ferrite in linepipe steels. Materials Science \&amp, 2008, 478(1-2): 361-70.

[9] T .Gladman. Precipitation hardening in metals. Materials Science and Technology,1999,15(1):30-36.

[10]B.X. Liu, F.X. Yin, X.L. Dai, J.N. He, W. Fang, C.X. Chen and Y.C. Dong. The tensile behaviors and fracture characteristics of stainless steel clad plates with different interfacial status.Materials Science \&Engineering A, http://dx.doi.org/10.1016/j.msea.2016.10.033

[11]Zhi-chao Zhu, Yi He, Xin-jin Zhang, Hui-yun Liu, Xiao Li. Effect of interface oxides on shear properties of hot-rolled stainless steel clad plate. Materials Science \& Engineering A, 2016 (669): 344-349 